\title{
A Review of Translation Teaching Researches from the perspective of Eco-Translatology
}

\author{
Gao Ning
}

School of Foreign Studies, Yangtze University, Hubei, 434023 PRC China

Received: 11 May 2021; Received in revised form: 01 Jun 2021; Accepted: 10 Jun 2021

C2021 The Author(s). Published by TheShillonga. This is an open access article under the CC BY license

(https://creativecommons.org/licenses/by/4.0/)

\begin{abstract}
Eco-translatology is a holistic study of translation from an ecological perspective. It began in China in 2001. It has filled the gap in the study of the "ecological dimension" of translation studies and promoted the development of translation theory in China. This article gives a brief overview of Eco-translatology studies. The author classifies the current translation teaching researches under the perspective of Eco-translatology; point outs the existing problems and shortcomings; and puts forward some opinions on translation teaching researches from the view of Eco-translatology, expecting to provide reference for future ecological translation studies.
\end{abstract}

Keywords-Eco-translatology, translation teaching researches, translational eco-environment.

\section{INTRODUCTION}

Eco-translatology was first introduced in 2001 by Professor Hu Gengshen in his paper An Initial Exploration into an Approach to Translation as Adaptation and Selection presented at the 3rd FIT Asian Translators' Forum. This paper redefines translation from the perspective of adaptation and selection, illustrates the relationship between translator adaptation and translator selection, and makes a new description of the process, principles and methods of translation from the perspective of adaptive selection. It initially forms the basic framework of translation as adaptation selection theory (Haggers, 2011).The publication of his monograph Eco-translatology: Construction and Interpretation $(\mathrm{Hu}$, 2013) was the manifesto for the birth of Eco-translatology. It has formed its own ten core concepts, including the theory of "Textual Transplants" of translated texts, the theory of "Translator Responsibility" of translation subjects, the theory of "Ecological Equilibrium" of translation ecology, and the theory of "Text-Translator-Translational eco-environment" of research perspective, an approach to Translation as Adaptation and Selection of translation performance,, the theory of "Three Stages of Translation" in translation progress, the theory of "Degree of Holistic Adaptation and Selection" in translation criterion, and the theory of "Survival of the Fittest "of the translations, the theory of "Doing Things with Translations", and the theory of " the Relevance Chain" in the development of translation studies. Viewed as an interdisciplinary research approach, Eco-translatology also has strong effect in explaining and guiding the translation teaching practice.

In Eco-translatology, the theories often applied to translation teaching include translational " translational eco-environment" "translator-centered" theory, "entirety / relevance" theory, and "ecological equilibrium" theory.

The translational eco-environment can be defined as the sum of all the external conditions that affect the survival and development of the translator. In a broad sense, The subject here is all organisms involved in translation activities, including original authors, translators, readers, initiators, sponsors, publishers, marketers, editors 
and so on (Hu, 2013). All those factors can viewed as the members of "translation community". The extern al environment may include the natural and economic environment, linguistic and cultural environment, social and political environment which is related to translation activities. The translational eco-environment is intertwined by various elements, which is the sum of all kinds of natural and humanistic factors in the occurrence, existence and development of translation activities.

Translational eco-environment is a key term in Eco-translatology. During the early stage, Eco-translatology described translation as the translator's selection to adapt to the translational eco-environment to transplant the text. The translation process is translator's adaptation and selection. The translational eco-environment here also refers to the "world" presented by the source text, the source language and the target language. To be more specific, that is, language, communication, culture and society. And the "entirety" of the interaction of the author, the reader, the trustee, etc. (that is, the "translation community"). Translational eco-environment is a "collection" of many factors that restrict the translator's best adaptation and optimal selection. Here, "world", "entirety" and "collection" refer to the "synthesis" of the ecological environment related to translation. Therefore, translational eco-environment can be explained from three levels: large environment, medium environment and small environment, and also there are the differences between the external environment and the internal environment; it includes not only the object environment (such as the original text, translation, stylistic function, translation strategy, translation stipulation, etc.) and the subject environment (translator, author, reader, publisher, negotiator, reviewer, etc.), andthe material environment and spiritual environment, and so on.

$\mathrm{Hu}$ (2014) points out that the concept of "translator-centered" in the translation process are becoming mature and rational, and are also going through the test of time and practice. The main reason can support this statement is that 'translator-centered' theory can be illustrated from two levels: one is 'translator- dominated ' theory at the micro-level and in the translation process. The other is the translator responsibility at the macro level and at the ethical level of translation. Translator responsibility mainly refers to the responsibility of the translator in the overall translation activities, that is, the translator has the responsibility to coordinate the relationship between all parties, to keep ecological rationality, to maintain ecological equilibrium, and to maintain ecological harmony. Translator has responsibility to adapt to the ecological equilibrium, cultivate the ecology of the target language, pay attention to the acceptance and dissemination of the target text, and strive for the survival and long-term survival of the translated product. In other words, the translator presents the balanced and harmonious ecological holistic view of translation through the principle of translator responsibility.

The connotation of "entirety / relevance" in ecology is to attach importance to individual dependence on the overall environment (Hu, 2013). The interrelation and interaction between the various components of the system will make the system a unified and interrelated whole. The function of the entirety is also greater than the sum of the functions of the various components. Changes in any of these components in the ecosystem will lead to changes in other components. This is true of natural ecosystems, and the same is true of translational ecosystem. There is an inherent mutual interaction and overlapping parts among the components in the translational ecosystem, which makes the translational ecosystem an extremely complex entirety. Therefore, in the study of translational ecosystem, it is far from enough to study a certain sub-ecosystem in isolation. For example, when discussing the theoretical framework of translational ecology, we need to take into account the relationship between the translation management ecosystem and the translation market ecosystem, the relationship between the translation market ecosystem and the translation education ecosystem and so on.

Translation is a complex ecosystem. Because of the relevance, similarity and isomorphism between translation ecology and natural ecology, the balance in natural ecology also exists in the translation ecosystem. Only through the interaction between the subjects and objects of translation activities and between the subjects of translation activities and their external ecological environment can a dynamic balance system of translation 
ecology be developed. Generally speaking, the ability of self-regulation within the translational ecosystem depends on the ability of the "translation community" represented by the translator within the system.

Wang (2011) makes an insightful analysis of the research paradigm of Eco-translatology from the cognitive perspective of deconstruction. He believes that Eco-translatology has the dual significance of deconstruction and construction. Han (2012) pointed out that Eco-translatology has drawbacks stemmed from the evolutionary theory, such as concepts of translational eco-environment, survival of the fittest, and the principle preserve the strong and eliminate the weak. It is necessary to redefine the concept of ecological environment in ecological translation. There is no denying the fact that Eco-translatology guides researchers to pay attention to the environment, translators, translations, and the survival status of the translations, and opening up new paths for translation studies, is affirmed.

\section{TRANSLATION TEACHING FROM AN ECO-TRANSLATOLOGY PERSPECTIVE}

Eco-translatology has been rapidly developing and improving in recent years, which has attracted a group of scholars to begin to study its role in English translation learning and to explore practical solutions for translation teaching problems. At present, the authors found some relevant articles after searching on China National Knowledge Infrastructure, and those researches most focus on: teaching models of interpretation; teaching models of translation; reflections on and new understanding of traditional translation teaching concepts; re-examining Chinese translation teaching materials from the perspective of ecological translation studies; reflections on translation teaching; and combining ecological translation studies with corpus translation teaching.

First, the researches on the teaching model of interpretation. As a new interdisciplinary theory of translatology, Eco-translatology brings a new perspective and research methods to the teaching of interpretation. With the demonstration of project-based learning and instruction mode, Deng (2012) interprets how Eco-translatology works in the teaching approach of in interpretation and attends to establish a new mode for MTI
Interpretation from five perspectives including theoretic basis, objectives, preconditions, procedures and evaluation, the purpose of which is to cultivate the automation of interpretation skills, sustainable development of the interpreter capability, thus the harmony of interpretation eco-environment could be well achieved. In addition, this model emphasizes the dominant position of learners in the ecological environment of interpretation, their active experience in the thinking process of interpretation, and pays special attention to the application of the principles of Adaptation and Selection and Post-event penalty in the process of interpretation.

From the perspective of Eco-translatology, the article wrote by Sun (2017) explores the essential concepts of interpreting training modes and the composition of eco-interpreting competence, and constructs a multi-dimensional and dynamic eco-interpreting training mode. It discusses how to develop eco-interpreting competence in terms of six components of the mode, namely source language comprehension, target language delivery, discourse and context analysis, interpreting skills, cross-cultural communication via extra-language knowledge, and psychological quality of the interpreter. The eco-interpreting training mode is to boost the adaptive and selective ability of the interpreter in the eco-interpreting environment, and to bring a new approach to interpreting teaching study. Although this set of ecological interpretation training model has brought about a new path of interpretation teaching research with a distinct interdisciplinary nature, it has the same shortcomings as Deng's interpretation teaching model, and its practical application effect has not been proved by the way of empirical research. Therefore, the drawbacks existing in these two models and the ways to improve them also need to be further explored. Zhang (2011) proposes that the interpretation model from the perspective of Eco-translatology includes two aspects: survival of the fittest is the basis of the ecological interpretation model, and interpreters actively integrate into the interpretation environment and reserve their own opinions while merging. The organic combination of self-publicity and adaptation to the environment, and finally realize the establishment of the ecological network of interpretation. Harmony and unity is the principle of the ecological interpretation model. 
In the ecological interpretation model, the interpreter is the mediator who connects the ecological interpretation activities and connects the ecological chain of the source language with the target language to form a harmonious and unified environment. There are also a scholar (Zhang Wei, 2016) who take Eco-translatology as a theoretical basis and culture-loaded words as a research focus to study interpretation teaching. This study finds that translators must strengthen their understanding of the cultural connotations of different nationalities, societies and cultures in the process of translating of culture-loaded words in order to ensure the accuracy of the translation.

Second, the researches on the teaching mode of translation. First of all, some scholars take their own universities as an example to elaborate on the application of Eco-translatology to the study of translation teaching model. Sheng (2015) takes China Three Gorges University as an example to explore the construction of translation teaching model for English majors from the perspective of Eco-translatology. It emphasizes the dynamic balance among many related factors, such as teaching orientation, teaching objectives, teaching content selection, teaching subjects, curriculum resources, teaching evaluation system and the regional market demand of Yichang tourism city. According to Eco-translatology, in the process of translation teaching, translators should pay close attention to the translation ecological environment of the text and make different degrees of dynamic choices to adapt to this environment. Teachers and students should become the two subjects in the ecological environment of translation, and the relationship between them should be changed from "giving" and "receiving" to equal interaction. Only the continuous improvement of the ecological translation teaching model, the sustainable development of the ecological translation system, the improvement of students' translation ability can achieve the goal of yielding qualified translators. Characterized by tea culture in Xinyang, Zhuang's paper (2016) combines the concept of "dynamic/ balance" with the process of translation teaching method with distinctive teaching objectives and teaching contents, relates the concept of "entirety / relevance" to the simulated ecological environment of translation teaching, and applies "diversity / unity" to translator-centered teaching methods in the teaching of tea culture translation.

In addition to taking their own universities as examples, some scholars apply Eco-translatology into teaching model from the angle of clothing translation and CET-4 paragraph translation. Analyzing the specific connotation of the "learner-centered" teaching concept in the teaching practice, Zhang and $\mathrm{Xu}$ (2013) focus on the teaching of clothing translation courses. Their paper probes into the teaching of "learner-centered" translation courses from the following aspects: ecological environment, the setting of teaching objectives and the selection of translation materials, after-class assignments and the evaluation of learners' learning effect. This paper demonstrates the feasibility of implementing "learner-centered" translation teaching in the ecological environment, and puts forward the corresponding measures in the light of the difficulties existing in the teaching. Cheng (2014) takes the paragraph translation from CET-4 as the research object, takes Eco-translatology as the theoretical basis and tries to establish a good ecological translation system according to the relationship of "dynamic/ balance", "entirety / relevance" and so on, which provide effective guidance for college English translation teaching.

There are few empirical studies on translation teaching model from the perspective of Eco-translatology. Shu (2014) integrates Eco-translatology into the translation teaching model to build a complementary system for cultivating students' translation ability and a harmonious and unified ecological environment for translation teaching. This study is characterized by the fact that students take on different roles and play a real role in translation projects. The advantage of this study is that t-test is used to demonstrate that the translation teaching model under the guidance of Eco-translatology can help students improve their translation ability, learn languages through translation, and they can also learn the information you need through the language. Wang (2015) takes the undergraduate English majors from Dalian University of Technology as the research object to make a comparative study of the effectiveness of the traditional deductive and ecological interpretation teaching model by means of tests and questionnaire survey. This study finds that Eco-translatology provides scientific teaching theories and teaching methods that develops learners' bilingual 
communicative competence, cross-cultural awareness, encyclopedic knowledge and working language ability at the macro level. Without interpretation learners' good cooperation, Class teaching tasks can not be completed efficiently, and students take part in the learning tasks enthusiastically or perfunctorily will also lead to the polarized test results.

Third, rethink Chinese translation textbooks from the perspective of Eco-translatology. On the basis of summarizing the development of Chinese translation textbooks, Tao (2012) introduces the compilation, development and relevant studies of translation textbooks in the ecological environment of Chinese translation. This paper points out that the construction of teaching materials for translation majors in the new century should follow the basic ideas of ecological design: build a harmonious ecological environment of translation textbooks, encourage the interaction among editors, publishers and users of translation textbooks, establish a good ecological relationship of knowledge, strengthen the connection between translation knowledge and life, learners' personal experience and related disciplines, explain knowledge in a descriptive way, because the more room for learners to think, the more enlightening lesson for learners to think to learn, and the more the critical thinking ability and research ability of translators can be cultivated. In all, Translation textbooks are no longer static, but pluralistic and dynamic, in the process of continuous generation and adjustment.

Fourth, reflection on translation teaching. Song (2012) concluded that the core connotation of ecosystem in Eco-translatology is holistic relevance, and the holistic study based on the methodology of ecological holism is one of the main conceptions of Eco-translatology. By reflecting the translation teaching system from a holistic perspective, we can find the interrelation, mutual restriction and interaction among the components, reveal the internal relevance of the translation teaching system, put forward a new understanding for some traditional teaching ideas, and provide a new way to explain some confusing phenomena in teaching practice. Cheng (2011) regards translation teaching as an ecological environment system and proposes to construct an ecological environment for translation teaching. The purpose of this paper is to cultivate the behavioral ecology of students' learning and teachers' teaching, as well as a flexible bilingual teaching model, so as to improve the initiative of foreign language learning and provide guidance for translation teaching activities.

Fifth, apply Eco-translatology into corpus translation teaching. Zhu and Wang (2018) point out that with a large number of real cases and effective statistical analysis of data, the corpus-based translation teaching model can enable translators to obtain different translation skills intuitively and objectively, and assist students to form their own translation ability, so as to effectively promote the improvement of translation teaching quality. The two scholars try to integrate translation teaching from the perspective of ecological translatology with corpus linguistics, combined with free Internet resources and related software, and combined with the strong industry background and unique language structure of Water Conservancy English. the behavior of constructing the corpus of water conservancy English translation teaching is commendable and innovative.

\section{CONCLUSION}

As a translation theory put forward by the Chinese scholar, there are relatively few studies concerning the application of Eco-translatology into translation teaching, and there are spme suggestions from the following three aspects: For one thing, there are few articles on the application of Eco-translatology into translation teaching, and not to mention that those can be published by the authoritative journals. There are less than 10 those kind of articles are published on Chinese authoritative journal. For another thing, the research methods used in those papers need to be improved. In order to make those kind of researches more objective, this paper advocates that more research should try to use the research methods of investigation, statistical analysis and tests. Some scholars who have proposed the ecological translation teaching model are supposed to conduct tests to prove its feasibility. Moreover, those kind of researches should be further deepened. Most researchers apply translational eco-environment, learner-centered view, "dynamic/ balance", "entirety / relevance" to translation teaching studies. However, other important concepts of 
Eco-translatology, such as the theory of "Survival of the Fittest" of the translations, the theory of "Doing Things with Translations", and the theory of "the Relevance Chain" have not been deeply applied to translation teaching. This thesis classifies and summarizes the current situation of translation teaching research from the perspective of ecological translatology, analyzes the existing problems, and puts forward reasonable suggestions for future research.

\section{REFERENCES}

[1] Cheng, A. Q. A study of College English Translation Teaching from the Perspective of Eco-Translatology [J]. Journal of Kaifeng Institute of Education, 2014, 34(10): 104-105.

[2] Cheng, Y. Translation teaching ecology: the macro environment and micro environment [J]. Journal of Jiamusi Vocational Institute, 2011(02): 355+357.

[3] Deng, Y. A Study on the Project-Based Learning and Instruction Mode of MTI Interpretation under the Framework of Eco-Translatology[J]. Technology Enhanced Foreign Language Education, 2012(05): 77-80.

[4] Haggers, S. A report on Eco-translatology: Ten Progress in Ten years of Researches [J]. Shanghai Journal of Translators, 2011, 109(4): 1-6.

[5] Han, W. Reinvestigation of "Translational Eco-environment" and "Survival of the Fittest"[J]. Foreign Language Research, 2013(01): 122-126.

[6] Hu,G. S. Eco-Translatology Construction \& Interpretation [M]. Beijing: The Commercial Press, 2013.

[7] Sheng, L. Construction of Translation Teaching Mode From the Perspective of Eco - translatology [J]. Journal of Jixi University, 2015, 15(03): 89-92.

[8] Shu,X. Y. An empirical study on Translation Teaching Model from the Perspective of Ecological Translatology [J] Shanghai Journal of Translators, 2014(02): 75-78+95.

[9] Song, Z. P. Reflection on Translation Teaching from the Perspective of Eco-Translatology [J]. Minority Translators Journal, 2012(03): 84-90.

[10] Sun, A. N. A Research on Constructing a Multi-dimensional and Dynamic Eco-interpreting Training Mode [J]. Foreign Language World, 2017(01): 72-78.

[11] Tao,Y. L. Interpreting Chinese Translation Textbooks from an Eco-translatological Perspective [J]. Foreign Language
World, 2012(03): 81-88.

[12] Wang, N. Ecological Literature and Ecological Translation: Deconstruction and Construction [J]. Chinese Translators Journal, 2011, 32(02): 10-15+95.

[13] Wang, J. N. Study on teaching mode of English major interpretation underframework of Eco-translatology [J]. Research in Teaching, 2015, 38(06): 60-63.

[14] Zhang, H. Q. \& Xu, J. A Study Probing into the learner-centered teaching methodology under the ecological situation [J]. Foreign Languages and Their Teaching, 2013(03): 41-43.

[15] Zhang, L. Y. A New Perspective in Research on Interpretation-Mode of Eco-Interpretation [J]. Technology Enhanced Foreign Language Education, 2011 (02): 76-80.

[16] Zhuang, S. S. A study on the subliminal Translation Teaching Model of Ecological Translation Studies-- taking Tea Culture Translation as an example [J]. Contemporary Education Research and Teaching Practice, 2016(08): 192-193.

[17] Zhang, W. A study on Culture-loaded Words and Interpretation Teaching from the Perspective of Eco-Translatology [J]. China Training, 2016(10): 64-65.

[18] Zhu, X. X. \&Wang, L. The Teaching of Corpus Translation in the Perspective of Ecological Translation [J]. Theory and Practice of Education, 2018, 38(12): 55-56. 